\title{
Epidemiological Sociology (Part One of Two): "Sociology in Epidemiology". Sociology as an Instrument of Epidemiological Analysis
}

\section{Turabian JL*}

Specialist in Family and Community Medicine, Health Center Santa Maria de Benquerencia. Regional Health Service of Castilla la Mancha (SESCAM), Toledo, Spain

*Corresponding author: Jose Luis Turabian, Health Center Santa Maria de Benquerencia Toledo, Spain, Email: jturabianf@hotmail.com

\section{Review Article \\ Volume 3 Issue 2}

Received Date: August 14, 2019

Published Date: October 17, 2019

DOI: $10.23880 /$ eij-16000127

\section{Abstract}

There are barriers to crossing the boundaries between sociology and epidemiology, due to the history of both disciplines, the definitions of their fields of study and the objectives of study, as well as the concepts and characteristic constructs. Sociological roles imply the articulation of social causality in the epidemiological study of health ("sociology in epidemiology": the study of the influence of the political and social environment on disease and health systems). The study of epidemiology can begin with a non-problematic ontological reality of health and illness, but have to ends up problematizing the very concept of health-disease, demonstrating that the study of health determinants also requires the study of the determinants of the social construction of disease. This article aims to reflect on the boundaries between sociology and epidemiology, and how the arguments of epidemiology can be modified or nuanced by sociological evidences. Thus, certain sociological concepts modify the biomedical epidemiological view and they need to be approach by epidemiological sociology. Some examples are: social capital, empowerment, stress, social support and coping, race, globalization, transnational actors and traditional national and local governmental actors, migrations, multiculturalism, mobility, personal life, intimacy, relationships and families, housing, political, economic and cultural factors which structure the drugs prescriptions, community fragility, the dominant social contexts related to environmental impact and the depletion of staple foods in conditions such as climate change, etc. These sociological factors are generally not considered in the basic approaches of epidemiology, and yet they are fundamental to understanding the role of health and disease development.

Keywords: Sociology; Socialization; Epidemiology; Sociology, Framework; Public Health; Political Motivation; Social Influence; Social Power; Policy; Power Relations

\section{Introduction}

Epidemiology is the study of the distribution and determinants of health-related states or events (including disease), and the application of this study to the control of diseases and other health problems. Various methods can be used to carry out epidemiological investigations, from surveillance and 
descriptive studies for studying health/ disease distribution, until analytical studies for study the determinants of health/ disease [1].

Thus, epidemiology studies can be described as the examination of the frequency, magnitude and distribution of diseases in human populations. In fact, it is considered a branch of public health that aims to describe and explain the dynamics of population health in order to propose strategies and intervention actions. Faced with this way of defining epidemiology, from the social sciences the subdisciplines of anthropology and medical sociology were formed [2].

Epidemiology has a series of related sciences: medicine, biostatistics, biology, biochemistry, demography, ecology, economics, entomology, psychology, informatics, bacteriology, immunology, parasitology, nutrition, toxicology, public health, and sociology. In this regard, sociology is the social science that studies the collective phenomena produced by the social activity of human beings, within the historical cultural context in which they are immersed [3].

Health sciences are typically frontier sciences. The solutions arise from the contact areas between medicine, biology, pharmacology, chemistry, social sciences, etc. To approach the sphere of health, independently of the social sphere, would be to assume an abstract and unilateral model that would give us a distorted vision of reality, since the man who wants to provide health is a living being who thinks, feels, acts and he or she develops in society. The consideration of the social in the medical sciences and practice, as well as the social determination of health and the need of the social sciences for their scientific understanding, is something widely recognized [4].

Moving a little further, sociology is defined as the study of the origin, development, organization, and functioning of human society [5]. Sociology has been classically defined as the science that studies the regularities of the development and functioning of social systems, both global and particular [6]. Sociology studies the concatenation of different social phenomena and the regularities of man's social behavior. A more pragmatic definition indicates that it deals with human social life, groups and societies [7].

The sociological approach is very useful in the practice of health actions to determine the problem in its multifactorial character. Sociology, together with epidemiology, helps measure its impact; but, in addition, it facilitates the establishment of existing relationships between living conditions, certain behaviors and risk factors that can develop diseases. When dealing with this relationship between social factors, health and illness, the health professional enters into more complex relationships, such as the influence of illness or health on behavior and vice versa. This reciprocal dependence between epidemiology and sociology is influenced by the relationship of man with his social environment, by the socioeconomic position he occupies in this environment and by his social behavior proper [4].

From all the above it is clear that the development of health is not an individual problem, but a condition and consequence of social action, but that, in turn, has an individual response that depends on the type of condition, personality and functioning of social mediations in the face of illness. But, the integration of sociology and epidemiology is an infrequent situation [8]. In fact, the gap between sociology and medicine, that is, the interface between sociology and health has expanded, and there are persistent difficulties in relation to the structure and approach of the health system, the power of the school of medicine and the culture of doctors and medical students [9].

However, sociological roles imply the articulation of social causality in the epidemiological study of health ("sociology in epidemiology"), together with the articulation within the sociology of the importance of the study of epidemiology ("sociology of epidemiology"). The advantage of this double role, of looking outwards and at the same time looking inward, is that we can take advantage of essential developments and innovations from one source and "move" these ideas towards the other. The difficulties of this position are also clear: as an area, we can be structurally marginal from both perspectives, at the same time that we offer considerable analytical power that could significantly impact the direction of research that involves health in both areas [10].

By means of the different sociological approaches to epidemiology topics -descriptive, evaluative, and analytical-, the epidemiology will benefit by using the tools of sociology to answer its questions ("sociology in epidemiology") and, on the other hand, by allowing sociology to have epidemiology as the object of its study to answer sociological questions ("sociology of epidemiology") [11].

Although from the point of view of the spelling, there is only a small difference between "sociology in epidemiology" and "sociology of epidemiology", really if there is a big difference, although only initially, between "sociology in epidemiology" (it is a collaborator of health institutions), and the "sociology of epidemiology" (it is independent of health institutions, and it can analyze the discipline of epidemiology). When sociology in epidemiology is consistent, it should become sociology of epidemiology. 
For example, the study of the social determinants of health and illness begins by assuming nonproblematically the ontological reality of health and illness, but ends up problematizing the very concept of health-disease, demonstrating that the study of health determinants also requires the study of the social determinants in the construction of disease.

So, there is a urgent necessity of applying sociological tools which can examine the so-called objective factors in the determination of health and disease, the socially constructed nature of these categories of knowledge, and the struggles and power relations that determine whether or not such categories are viable [12].

Important convergences and divergences between sociology and epidemiology can be described, related to a series of problematic areas that can hinder the tendency to cross borders between sociology and epidemiology, such as the history of both disciplines, the definitions of their fields in study and study objectives, as well as the characteristic concepts and constructs [13].

A conceptual framework for understanding the relationship of epidemiology, and sociology has been described. There are several empirical contributions by sociologists to the field of epidemiology (contributions by Durkheim, Dunham, Hollingshead, and sociological theories as stratification theory, symbolic interactionism, and the sociology of knowledge, etc.) but the two major contributions of sociology to epidemiology are the concepts and data related to the social fact, and the possibilities offered by the sociological imagination $[14,15]$.

In this scenario, this article, the first part of two texts, based on the author's experience and a narrative review, aims to reflect on the "sociology in epidemiology", on these interferences between medical sociology and epidemiology, and how the arguments of epidemiology can be modified or it can be nuanced, by sociological evidences.

\section{Discussion}

Social epidemiology is the field of research that refers to the role of social and psychological factors in the etiology of diseases. According to some authors, the term social epidemiology is a redundancy, since the social-collective is already contained in the object of knowledge of epidemiological science. Social epidemiology has the vocation to provide useful information on which public policies increase or decrease inequalities in health. It is the polar opposite of the dominant epidemiology, which operates with individual risk factors, disregards social variables (social class, income, education, ethnicity, country of origin, etc.) and advocates a "depoliticization" of the practice. Social epidemiology is mainly focused on studies on social inequalities in health, especially from the comparison of the distribution of indicators, such as perceived health, mortality, prevalence of individual risk factors of chronic diseases or tumors or prevalence of mental illnesses, with the distribution of indicators of socioeconomic position and even with the different socio-political contexts [16].

On the other hand, from Rudolf Virchow (18211902) the inseparable union between medicine and politics is underlined: medicine is not simply the study of the disease but a general metaphor for understanding society. Virchow's social medicine was based on rigorous research and decisive intervention to cure social disease [17].

In addition, it can be pointed out the reconceptualization efforts that were made in the 70s of the last century, and that gave meaning to research on stress, traits or types of personalities and social support. However, despite this, this tradition of research places too much emphasis on the identification of risk factors, while underestimating the explanation of the conditions in which good health is maintained [18].

Traditionally, medical textbooks classify diseases by the organ system affected, that is, respiratory or digestive system diseases, etc., and frequently by the agent involved, for example, viral or rickettsial or bacterial diseases. Epidemiological writings use, in addition, classifications based on the vector, that is, diseases are classified water-borne, insect-borne and the like. Since the 70s of the last century it has been suggested that another way of classifying diseases could develop from the paradigm just discussed. Thus, for example, it can be speak about diseases in terms of the social situation in which they occur. Some diseases might be classified, for example, as poverty-related diseases. These would include cancer of the cervix and tuberculosis and many others. Again, there might be a classification of upper class diseases-for example, cancer of the breast and corpus uteri. Another category of social situation which might serve to categorize disease might be labelled familial instability-related conditions. This could include, as has already been suggested, diseases related to divorce, separation, and widowhood. Moving to individual behavior patterns, we could cite alcohol-related conditions, such as cirrhosis, malnutrition, and accidents, or smoking related diseases, such as lung cancer, coronary heart disease and emphysema. The same could be done in relation to climate change or environmental conditions, migrations, race, gender, etc [19]. 
A "new" basic analysis must have a change of direction from that of the past, since social processes now largely determine the pattern of development of health / disease. These new basic analyzes should include problems that were never part of the previous basic analyzes, such as problems of environmental impact and the depletion of staple foods in conditions such as climate change. Several factors provide the dominant social contexts to analyze the development of health / disease at present. Among them are the rise of neoliberal governments, the implementation of globalization and its social consequences, the assumption of aboriginal rights, and the rise of environmentalism. These factors were generally not considered in the basic approaches of epidemiology, and are fundamental to understanding the role of health / disease development [20].

The sociology of the disease explores the dialectic between social life and illness, with the aim of examining whether social life is important for morbidity and mortality and vice versa [21].

When biomedical knowledge and technology create the capacity for humans to avoid disease and prevent early death, sociological factors become more important and no less important for the health of the population. Transforming the cause of the disease from a cruel fate, accident and bad luck to circumstances that are under some degree of human control, facilitates a powerful social formation of disease and death. When humans have control, it is their policies, their knowledge and their behaviors that shape the consequences of biomedical achievements and, therefore, existing patterns of disease and death. Therefore, a "social configuration approach" that could frame our understanding of these processes and allow us to take measures to optimize the health of the population would be necessary. Support for this approach is obtained from the evidence of dramatic improvements in the health of the population and in the unequal distribution of those improvements among people, places and times. Improvements in health suggest that humans have gained control of the disease, while the uneven and very slow spread of such improvements underscores the critical importance of social factors [22].

There are important social dimensions that underlie social organization, culture and behavior that have dramatic repercussions on health / disease. The almost exclusive dependence on the biomedical model of diagnosis and epidemiological study of the disease shows us a distorted view of the burden of disease and disability in the community. With the aging of populations and the increasing prevalence of chronic diseases and disabilities and behavioral disorders, new approaches are needed for patient assessment and intervention to expand traditional models, including social and environmental policy concepts. At the same time, the health / disease and disability process should be deployed, so that social movements help define and redefine these conceptions of disease and disability [23].

Five major areas of research included in the category of sociology of medicine can be described, such as the consumption of medical care; the social, cultural and economic environments related to health and illness; health behavior and illness; patient education; and the evaluation of the services provided to the consumer [24].

Sociology, within epidemiology, is one of the main instruments to be used to know the phenomenon of health and disease (Figure 1).

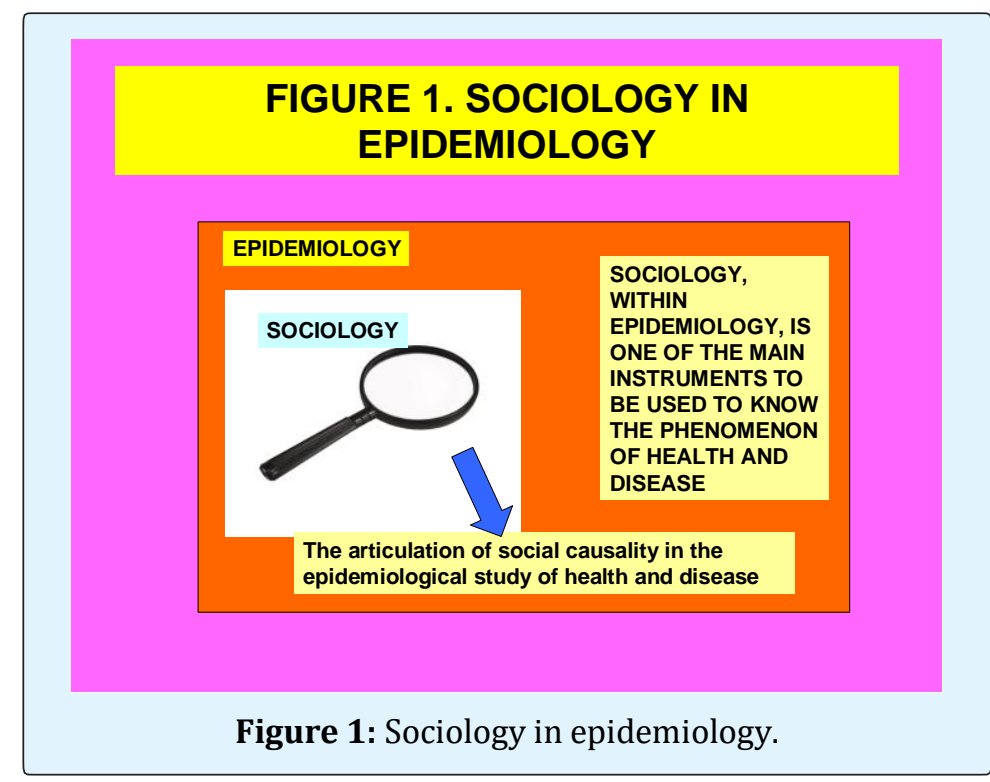

Turabian JL. Epidemiological Sociology (Part One of Two): "Sociology in Epidemiology". Sociology as an Instrument of Epidemiological Analysis. 


\section{Epidemiology International Journal}

In relation to all this, it can be said that an epidemiological sociology is needed rather than a social epidemiology. Among the sociological concepts that modify the biomedical epidemiological vision and can bring us closer to a "sociology in epidemiology", we can cite, as examples (Table 1):

\begin{tabular}{|c|c|}
\hline S.No & Concepts \\
\hline 1 & Social capital and Empowerment \\
\hline 2 & Race and gender \\
\hline 3 & Globalization, transnational actors and traditional national and local government actors \\
\hline 4 & Multiculturalism \\
\hline 5 & Diverse mobilities of peoples, objects, images, information, and wastes \\
\hline 6 & Environment \\
\hline 7 & Personal life, intimacy, relationships and families \\
\hline 8 & Stress, social support and coping \\
\hline 9 & Housing \\
\hline 10 & Colitical, economic and cultural factors which structure the drugs prescriptions \\
\hline 11 & Community \\
\hline 12 & Social context \\
\hline 13 & Work \\
\hline 14 & From sero-epidemiology to sero-sociology \\
\hline 15 & Obesity \\
\hline 16 & Tholecular sociology" of the cell \\
\hline 17 & \\
\hline 18 & \\
\hline
\end{tabular}

Table 1: Examples of Concepts about "Sociology in Epidemiology".

1. Social capital and Empowerment. These concepts taken from the social sciences have emerged in epidemiological studies as new factors, improving our understanding of the relationships between social inequalities and health inequalities [25].

2. Race and gender. There have been two distinctly organized institutional sociological thinking traditions about race: one black and one white. For the most part, the dominant epidemiological approaches have kept silence about this segregation and, in the best of cases, reproduce it [26]. For example, notions of race have been invoked and constructed in relation to heart disease through efforts such as the Framingham stud [27]. On the other hand, research in health in general, and also epidemiological research, has omitted the study of inequalities in health derived from the unequal social position of women and men - gender inequalities - for a long time: sexual division of labour, the burden of family care that is supported mainly by women, etc [28,29].

3. Globalization, transnational actors and traditional national and local government actors. For example, infectious diseases have resurfaced as a threat to public health in an increasingly globalized era, adding transnational actors to traditional national and local government actors. Epidemiology should investigate the social construction of new and re-emerging diseases; the development of surveillance systems, the governance of public health; the impact of scientific / technical modalities on uncertainty and risk, the interaction of infectious diseases, public health and national security problems, and the responses of the media and the public [30].

4. The migrations. For example, the cases of infections such as tuberculosis among immigrants (especially illegal immigrants) in developed countries which has increased recently as the number of foreigners increases. Immigrant patients present various challenges in the control of tuberculosis, with higher rates of abandonment of treatment and resistance to medications. the shorter the stay, the greater the incidence. This modifies guidelines to improve the detection of cases and the treatment of tuberculosis among immigrants, for example the importance and limitations of detection by chest radiography in the early stage of arrival can be underlined [31].

5. The multiculturalism. The incorporation of sociology in medicine and epidemiology should allow these disciplines to move towards a more "multicultural" approach [32].

6. Mobility. The mobility of peoples, objects, images, information and wastes appears. This brings with it a series of complex interdependencies and social consequences. A number of key concepts relevant to such an epidemiology should be elaborated: networks, fluids, flows, complexity or iteration [33].

7. Environment. Factors that provide the dominant social contexts, such as the rise of neoliberal governments, the implementation of globalization and its social consequences, the assumption of aboriginal 
rights, and the rise of environmentalism, to analyze the new problems related to the impact environment and the depletion of staple foods under conditions such as climate change [20]. As well as, air pollution, depletion of the ozone layer, contamination of drinking water supplies, damping of hazardous wastes, electromagnetic radiation, and agricultural practices that have adverse environmental effects, pollution of the seas, etc. Consequently, environmental epidemiology has evolved over the years with a broader understanding of the health effects of traditional hazards related to water and air pollution, contaminated foodstuff as well as hazardous wastes and a few toxic chemicals $[34,35]$.

8. Personal life, intimacy, relationships and families. The epidemiology of the family is increasingly understood as the epidemiology of "personal life", "intimacy", "relationships" and "families": the uncertainty of paternity, inheritance and family business, etc. The family should be conceptualized as an institutional regime where due consideration should be given to the reflexive reconfiguration of family relationships and practices, on the one hand, and their institutional integration, on the other [36].

9. Stress, social support and coping. These concepts should be evaluated more fruitfully in terms of their effects in limiting the number, severity and spread of disease / health $[37,38]$.

10. Housing. For example, infant mortality is twice as great in homes without bathtubs, although the infants do not use them, and increases with lower rentals. Housing is also not to be separated from cases of typhoid and respiratory disease. Health, education, standards, inspection, control of rent profiteering and a living wage are health factors related to housing [39].

11. Political, economic and cultural factors which structure the doctor drugs prescriptions. It requires a sociological approach to drugs prescriptions (For example, regarding the benzodiazepine tranquillizer prescribing). The analysis should be on both the micro level of the doctor-patient relationship and the macro level of those political, economic and cultural factors which structure the prescribing process [40].

Also, epidemiological approaches are needed on how patient characteristics, the physician's interaction with the health care system, and the physician's interaction with the patient who has a certain diagnosis, leads to receive drugs prescriptions prescribing. An especially important fact is that insurance status of patients who received an prescription, as antidepressants, etc $[41,42]$.

12. Community. Sociological concepts such as the concept of community fragility from a systems perspective, including ecosystems, social systems, socio-technical systems, and complex adaptive systems [43] should be incorporated into epidemiological studies. On the other hand, the concept of "community" is modified and replaced by "context"; The practice of community medicine is "contextual medicine", which means sharing and empowerment in the connections in the relational matrix of the patient, and this may favor contextual contextualization, that is to say the increase of individual capacity among people who participate in a group, and this action brings about a consequence about some kind of resources or control of the decisionmaking process [44].

13. "Lay health promotion". Two fears about traditional health promotion are been identified. The first concerns the ability to choose between proliferating expert advice, and the second concerns the fear of government interference in personal life. The epidemiology has to be a 'lay epidemiology' which has been overlooked by both critics and supporters of health promotion [45].

14. Social context. From an epidemiological point of view, qualitative data reveal that a similar disease is lived in various ways according to precise social context. In addition to the physical handicap objectively defended and to its social interpretation, must be also be analysed in the light of another important linking factor, the individuals' social status and specific task and obligations of various groups in a given population. Considered together, these factors provide a better understanding of the social condition of persons with diseases, their economic and matrimonial resulting in the conception of appropriate health programs [46].

15. Work. The main problems confronted in epidemiological investigations of occupational diseases are the absence of a definition of the diseases, the need for a standardized questionnaire for the symptoms of the disease and the heterogeneity of contexts [47].

16. from sero-epidemiology to sero-sociology. For example, to providing an objective measure of various aspects of sexual behavior: objective markers for sexual behavior and effects of intervention or educational approaches [48].

17. Obesity. The current obesity epidemic is largely driven by environmental factors, including nutritional transition towards refined and fatty foods with the growing production of energy-dense food at relatively low cost, increased access to motor vehicles, mechanisation of work and sedentary lifestyles [49].

18. The "molecular sociology" of the cell. This gap is now being bridged by using emerging experimental techniques, such as mass spectrometry of complexes and single-particle cryo-electron microscopy, to complement traditional biochemical and biophysical methods. With the development of integrative computational methods to exploit the data obtained, such hybrid approaches will uncover the molecular architectures, and perhaps even atomic models, of many protein complexes [50]. 


\section{Conclusion}

The sociological vision shows the factors that provide the dominant social contexts and in this way, taking into account this sociological contribution, facilitates the power to analyze the epidemiological changes of health / disease at present. These sociological factors are generally not considered in the basic approaches of epidemiology, and are fundamental to understanding the role of health and disease development. So, the arguments of epidemiology can be modified or nuanced by sociological evidences. In this way, a "new" basic epidemiological analysis must incorporate a change of direction with respect to the past, since social processes largely determine the pattern of development of health / disease. These new basic analyzes should include problems that were never part of the previous basic analyzes.

All these reflections would be ineffective if, when dealing with the interaction between sociology and health in daily practice, efforts were made to define the spheres of action of each of the different profiles of the profession, and so, some to focus on the biological, and others in the social. The focus must be on the man with his health problem. Once the problem is identified, the approach has to be with a multifactorial focus and an interdisciplinary work.

\section{References}

1. Epidemiology. WHO.

2. Aranda PG, Castro MV (2008) For a sociocultural epidemiology in the study of cervical cancer: research experiences. Región y sociedad 20(spe 2).

3. Epidemiología generalidades y ciencias afines (2015).

4. Pérez RN, González GR (2000) [Sociology and health. Reflections for action]. [Article in Spanish]. Rev Cubana Salud Pública; 26(2).

5. McGrath D (2009) The sociology of change. J Med Pract Manage 25(2): 105-110.

6. Rosendal M, Iudin P (1946) Diccionario filosófico Marxista. Montevideo (Uruguay): Ediciones Pueblos Unidos.

7. Giddens A (2000) Sociología. 3 $3^{\text {rd }}$ (Edn.), Madrid. Alianza.

8. Elford J, Chapman GE, Boothroyd Brooks EM, Shaper AG (1985) Population studies: an integrated course in epidemiology and sociology for medical students. Med Educ 19(3): 208-213.
9. Barros NF, Duarte Nunes E (2009) Sociology, medicine and the construction of health-related sociology. Rev Saude Publica 43(1): 169-175.

10. Wheaton B (2001) The role of sociology in the study of mental health ... and the role of mental health in the study of sociology. J Health Soc Behav 42(3): 221-234.

11. De Vries R (2004) How can we help? From "sociology in" to "sociology of" bioethics. J Law Med Ethics 32(2): 279-292.

12. Castro R (2016) [From sociology in medicine to the sociology of collective health: contributions toward a necessary reflexivity]. Salud Colect 12(1): 71-83.

13. Spruit IP, Kromhout D (1987) Medical sociology and epidemiology: convergences, divergences and legitimate boundaries. Soc Sci Med 25(6): 579-587.

14. Eaton WW (1994) Social facts and the sociological imagination: the contributions of sociology to psychiatric epidemiology. Acta Psychiatr Scand Suppl 385: 25-38.

15. Wrigtt Mills C (1970) The sociological imagination. New York: Penguin Books Ltd.

16. Segura del Pozo J (2006) Field epidemiology and social epidemiology. Gac Sanit 20(2).

17. McNeely IF (2002) "Medicine on a grand Scale": Rudolf Virchow, liberalism, and the public health. London: The Wellcome Trust Centre for the History of Medicine at University College London. Occasional Publication, No: 1.

18. Renaud M (1987) From social epidemiology to the sociology of prevention: 15 years' research on the social etiology of disease. Rev Epidemiol Sante Publique 35(1): 3-19.

19. Graham S (1974) The Sociological Approach to Epidemiology. AJPH 64(11): 1046-1049.

20. Matthews R (2014) Committing Canadian sociology: developing a Canadian sociology and a sociology of Canada. Can Rev Sociol 51(2): 107-127.

21. Timmermans S, Haas S (2008) Towards a sociology of disease. Sociol Health Illn 30(5): 659-676.

22. Link BG (2008) Epidemiological sociology and the social shaping of population health. J Health Soc Behav 49(4): 367-384.

23. Mechanic D (1995) Sociological dimensions of illness behavior. Soc Sci Med 41(9): 1207-1216. 


\section{Epidemiology International Journal}

24. Chaska NL (1977) Medical sociology for whom? Mayo Clin Proc 52(12): 813-818.

25. Fassin D (2003) [Social capital, from sociology to epidemiology: critical analysis of a transfer across disciplines]. Rev Epidemiol Sante Publique 51(4): 403-413.

26. Bhambra GK (2014) A sociological dilemma: Race, segregation and US sociology. Curr Sociol 62(4): 472-92.

27. Pollock A, Jones DS (2015) Coronary Artery Disease and the Contours of Pharmaceuticalization. Soc Sci Med 131: 221-227.

28. Borrell C, Artazcoz L (2007) 5a monografía. Sociedad Española de Epidemiología. Investigación sobre género y salud. Cataluña: Sociedad Española de Epidemiología.

29. WHO (2018) Women and gender equity. Social determinants of health.

30. Dingwall R, Hoffman LM, Staniland K (2013) Introduction: why a Sociology of Pandemics? Sociol Health Illn 35(2): 167-173.

31. Ishikawa N (1995) Tuberculosis among immigrants in Japan--epidemiological, clinical and sociological features, and the future of control. Kekkaku 70(12): 691-703.

32. Mulholland J (1997) Assimilating sociology: critical reflections on the 'sociology in nursing' debate. J Adv Nurs 25(4): 844-852.

33. Urry J (2010) Mobile sociology. 2000. Br J Sociol 61 (Suppl 1): 347-366.

34. Zawide F (2005) The role of environmental epidemiology in environmental health decision making. Epidemiol 16(5): 147-148.

35. Hannigan J (2017) Toward a Sociology of Oceans. Can Rev Sociol 54(1): 8-27.

36. Gilding M (2010) Reflexivity over and above convention: the new orthodoxy in the sociology of personal life, formerly sociology of the family. Br J Sociol 61(4): 757-777.

37. Pearlin LI (1989) The sociological study of stress. J Health Soc Behav 30(3): 241-256.
38. Siegrist J (1995) Epidemiologic and medical sociological aspects of hypertension. Herz 20(5): 302-308.

39. Wile IS (1920) Sociological aspects of housing. Am J Public Health (N Y) 10(4): 327-331.

40. Gabe J (1990) Towards a sociology of tranquillizer prescribing. Br J Addict 85(1): 41-48.

41. Turabian JL (2019) Sociology of the Medical-Patient Relationship: Putting Flesh on the Bones of a Stick Figure. J General Medicine and Clinical Practice 2 (2): 034 .

42. Sleath B, Shih YC (2003) Sociological influences on antidepressant prescribing. Soc Sci Med 56(6): 1335-1344.

43. Hodges LR (2016) Systems fragility: The sociology of chaos. J Emerg Manag 14(3): 177-187.

44. Turabian JL (2018) Community medicine from the point of view of the general practitioner: Never plump your foot straight into your shoe in the morning. Int J Adv Commun Med 1(1): 44-50.

45. Bury M (1994) Health promotion and lay epidemiology: a sociological view. Health Care Anal 2(1): 23-30.

46. Jaffré Y, Moumouni A (1993) "To be blind", blindness between an epidemiological and a sociological definition. Bull Soc Pathol Exot 86(4): 295-299.

47. Kanceljak-Macan B (1992) Epidemiologic and sociologic aspects of occupational bronchial asthma. Arh Hig Rada Toksikol 43(1): 47-52.

48. Nahmias AJ, Lee FK, Beckman-Nahmias S (1990) Sero-epidemiological and -sociological patterns of herpes simplex virus infection in the world. Scand J Infect Dis Suppl 69: 19-36.

49. Rosengren A, Lissner L (2008) The sociology of obesity. Front Horm Res 36: 260-70.

50. Robinson CV, Sali A, Baumeister W (2007) The molecular sociology of the cell. Nature 450(7172): 973-82. 